\title{
Fine Motor Skills and Executive Function Both Contribute to Kindergarten Achievement
}

\author{
Claire E. Cameron \\ University of Virginia, Center for Advanced Study of \\ Teaching and Learning \\ William M. Murrah \\ University of Virginia, Center for Advanced Study of \\ Teaching and Learning \\ David Grissmer \\ University of Virginia, Center for Advanced Study of \\ Teaching and Learning
}

Laura L. Brock

College of Charleston

Lindsay H. Bell and

Samantha L. Worzalla

University of Michigan

Frederick J. Morrison

University of Michigan

\begin{abstract}
This study examined the contribution of executive function (EF) and multiple aspects of fine motor skills to achievement on 6 standardized assessments in a sample of middle-socioeconomic status kindergarteners. Three- and 4-year-olds' $(n=213)$ fine and gross motor skills were assessed in a home visit before kindergarten, EF was measured at fall of kindergarten, and Woodcock-Johnson III Tests of Academic Achievement were administered at fall and spring. Correlations indicated that EF and fine motor skills appeared distinct. Further, controlling for background variables, higher levels of both EF and fine motor skills, specifically design copy, predicted higher achievement on multiple subtests at kindergarten entry, as well as improvement from fall to spring. Implications for research on school readiness are discussed.
\end{abstract}

Many kindergarteners struggle to master the foundational behaviors that enable them to successfully engage in classroom learning (Rimm-Kaufman, Pianta, \& Cox, 2000). This is reflected in skill gaps at school entry between children from socio-demographically advantaged and disadvantaged backgrounds (Grissmer \& Eiseman, 2008). Researchers who have explored the long-term consequences of interventions have concluded that the early years are the most cost-effective time to intervene (Heckman, Stixrud, \& Urzua, 2006). Furthermore, successful intervention depends on identifying the readiness skills that predict long-term achievement and developing programs that can improve these skills early in the school trajectory.

Realizing that children's success in school depends upon their coordination of multiple skill sets, experts have called for an expanded definition

We gratefully thank the children and their families, teachers, and research staff who made this study possible. This work was funded by the National Institute of Child Health and Human Development (R01 HD27176) and the National Science Foundation (0111754 and 0815787).

Correspondence concerning this article should be addressed to Claire E. Cameron, 2200 Old Ivy Road, Charlottesville, VA 22903. Electronic mail may be sent to ccp2n@virginia.edu. of school readiness beyond traditional measures of literacy and mathematics competence (Pianta, Cox, \& Snow, 2007). For example, the broad construct represented by executive function (EF) including attentional shifting, working memory, and inhibitory control consistently contributes to later learning outcomes (Duncan et al., 2007; McClelland et al., 2007). Conceptually as well as empirically, EF and the tasks of schooling appear to be inextricably intertwined (Brooks \& Goldstein, 2007; Shonkoff \& Phillips, 2000). Grissmer, Grimm, Aiyer, Murrah, and Steele (2010) provide evidence that fine motor skills at kindergarten entrance predict later achievement as well as teacher-reported attention (a component of EF). Building on this work, the present study examines the role of fine motor skills and EF in early achievement, with methodological extensions of prior work.

\section{Links Between Fine Motor Skills and Achievement}

Scant research has examined the association between fine motor skills and achievement in

(C) 2012 The Authors

Child Development (c) 2012 Society for Research in Child Development, Inc. All rights reserved. 0009-3920/2012/8304-0010

DOI: $10.1111 / j .1467-8624.2012 .01768 . x$ 
typical school-age populations, despite the prevalence of motor tasks in schooling (Marr, Cermak, Cohn, \& Henderson, 2003). Instead, early studies examined clinical populations, focusing on the comormidity of motor and academic difficulties (Kephart, 1964; O’Donnell \& Eisenson, 1969). Fine motor skills are the strongest predictor of special education referral and the second strongest predictor of kindergarten retention controlling for vocabulary, auditory and visual skills, and sociodemographic factors (Roth, McCaul, \& Barnes, 1993). Motor difficulties have also been widely documented in clinical samples in a range of diagnoses including autism, attention deficit hyperactivity disorder (ADHD), and externalizing behavior disorders (Livesey, Keen, Rouse, \& White, 2006; Williams, Whiten, \& Singh, 2004). About $60 \%$ of children diagnosed with ADHD are also diagnosed with developmental coordination disorder, suggesting a co-occurrence of impairment in EF and motor processes (Sugden, Kirby, \& Dunford, 2008).

Early childhood professionals and curricula have long emphasized the importance of motor development (Bredekamp \& Copple, 1997; Lillard, 2005), and kindergarten teachers rate fine motor skills as a key aspect of school readiness (Johnson, Gallagher, Cook, \& Wong, 1995). By kindergarten, fine motor tasks are better predictors of reading achievement than gross motor tasks (Wolff, Gunnoe, \& Cohen, 1985). Children with strong fine motor skills measured with a composite demonstrate better mathematics performance at kindergarten entry and make greater mathematics gains over the year (Luo, Jose, Huntsinger, \& Pigott, 2007; Son \& Meisels, 2006).

In longitudinal work, children who had strong motor skills measured with a composite of fine and gross motor tasks in preschool attained higher levels of third-grade reading achievement (McPhillips \& Jordan-Black, 2007). Using three nationally representative data sets and controlling for a host of background variables and prior achievement, Grissmer et al. (2010) reported that a fine motor composite and teacher-rated attention measured at kindergarten entrance each strongly predict later achievement in reading and mathematics. Murrah (2010) also documented strong, distinct contributions of fine motor and EF measures to first-, third-, and fifth-grade mathematics and reading. This work is promising in that it suggests that fine motor and EF make separate contributions to early elementary school achievement. Nonetheless, both Grissmer et al. and Murrah used large-scale data sets that relied on composites of predictor or outcome measures, including a measure of $\mathrm{EF}$ that was based on teacher reports of attention. More information is therefore needed on how specific aspects of fine motor skill are associated with specific aspects of early achievement when controlling for a direct measure of EF.

Fine motor tests typically include multiple tasks with visual, cognitive, and manual dexterity demands (e.g., drawing with a pencil to either copy an external image, or spontaneously generate an image) and spatial organization (e.g., building with blocks). The ability to match motor movement with an external visual stimulus, such as copying a design, is more predictive of children's achievement than other motor skills, such as gross motor balance (Bart, Hajami, \& Bar-Haim, 2007; Sortor \& Kulp, 2003). When design copy was parsed from draw-a-person and draw-a-profile in the British Birth Cohort Study, it was the strongest fine motor predictor of later mathematics and reading (Grissmer et al., 2010). This is notable because the drawa-person task has traditionally been considered a proxy for overall cognitive ability (Chappell \& Steitz, 1993), but perhaps less reliably so for the current generation (Willcock, Imuta, \& Hayne, 2011). In another study, children who could copy designs well at kindergarten entry had higher teacher-rated reading, writing, math, and spelling through third grade (Taylor Kulp, 1999).

These investigations offer preliminary support for the notion that children who lack adequate fine motor skills, notably design copy skills, are likely to fall behind in other academic areas. This may be due in part to the fact that design copy is highly related to handwriting (Daly, Kelley, \& Krauss, 2003). Yet perceptual-motor interventions based on the early studies that linked motor deficits to achievement were eventually discredited as a remedy for reading disability (Kavale \& Mattson, 1983). There is renewed interest, however, in understanding how fine motor and academic skills are related (Grissmer et al., 2010; Son \& Meisels, 2006). Furthermore, a set of underlying cognitive processes that are relevant for design copy, handwriting, and achievement may play an important role in explaining this association.

\section{Motor Skills and Cognition in Early Learning and Development}

In a review of available evidence on motor and cognitive processes, Diamond (2000) described four conclusions. First, neuroimaging studies consistently indicate that tasks that activate the prefrontal cortex, an area of the brain associated with attention and $\mathrm{EF}$, also activate areas of the brain considered 
integral to motor processing, particularly the cerebellum. Second, damage to certain areas of either the prefrontal cortex or cerebellum results in a reduction of neural activity in parts of the other area, suggesting that these two neuroanatomical regions are interdependent in normal functioning. Third, children with diagnosed cognitive disorders, such as ADHD or dyslexia, often experience motor impairments; likewise, children with motor impairments often demonstrate learning difficulties. Fourth, Diamond suggested that EF plays a key role in regulating both cognitive and motor learning. This work indicates a foundational link between EF and motor skills, and a need to explore how each relates with later achievement.

Tasks that require complex motor control appear to tax finite cognitive resources more than do tasks with simple motor requirements. The "dual-task paradigm" has been used to document this pattern in infancy (Boudreau \& Bushnell, 2000). When infants who were trying to reach their caregiver were placed on an uneven surface with obstacles (high motor demand), they made more cognitive errors, such as attempting a circuitous route, than when placed on flat, open ground (low motor demand; Berger, 2010). This line of work suggests that responding to motor (or cognitive) demands can reduce performance in the alternate domain (Rapport et al., 2009). Acquiring new motor skills also provides infants with novel learning experiences. For example, when learning to locomote, infants become exposed to a new set of socioemotional experiences such as parents' corrective feedback and discipline (Campos, Kermoian, \& Zumbahlen, 1992). In an empirical demonstration of the learning that follows from motor milestones, infants who have mastered sitting can more easily hold and manipulate objects, and were more capable than same-age, nonsitting infants at recognizing the correct threedimensional shape in a computerized laboratory manipulation (Soska, Adolph, \& Johnson, 2010). At the same time, experts note that increases in infants' processing speed precede the emergence of walking and other motor achievements (Zelazo, 1984).

Moving to the early school years, most learning endeavors in the classroom have motor as well as cognitive components. Children initiate motor processes in academic tasks like cutting and pasting letters, using manipulatives to do mathematics, or clapping their hands to learn syllables. In an observational study of kindergarten classrooms, researchers found that $46 \%$ of the school day was devoted to fine motor activities. Of those fine motor activities, 42\% were paper-pencil (Marr et al.,
2003). School-age children who evidence automaticity in coordinating their motor skills may have greater processing capacity available to learn more complex concepts, including symbolic representation of letters and numbers (Berger, 2010; Holtzer et al., 2007). Similar to individuals diagnosed with ADHD and other EF deficits, children with poor motor skills will likely take longer to complete assignments and may be exposed to fewer learning experiences (Lawrence et al., 2002).

\section{Links Between EF and Achievement}

The present conceptualization of EF is that of a complex, multicomponent cognitive construct involved in planning and coordinating responses (Best \& Miller, 2010). Motor skills by definition involve physically acting upon the outside world, whereas EF is more inclusive and involves acting upon ideas, sometimes while simultaneously acting upon the outside world (Willingham, 1998). In other words, EF is a broad construct that encompasses multiple processes, including but not limited to motor-related processes. This study employs a comprehensive measure of $\mathrm{EF}$ that requires children to attend to commands, remember four rules, and inhibit impulses as they respond with gross motor actions (Cameron Ponitz, McClelland, Matthews, \& Morrison, 2009).

Associations among early EF and a range of achievement outcomes are well documented (Duncan et al., 2007; Mazzocco \& Kover, 2007). Children who are able to pay attention to tasks, remember directions and keep information in mind, and control their impulses to initiate more adaptive behaviors have greater success in school (McClelland, Acock, \& Morrison, 2006; Morrison, Cameron Ponitz, \& McClelland, 2010). Duncan et al. (2007) analyzed six international longitudinal data sets and found that measures of attention (including parent-teacher reports as proxies for $\mathrm{EF}$ ) make consistent contributions to achievement. Furthermore, strong EF and related skills are positively associated with multiple measures of adaptive well-being in adolescence and beyond (Duckworth \& Seligman, 2005; Entwisle, Alexander, \& Olson, 2005).

\section{The Present Study}

The literature reviewed here has several limitations. First, almost none of the empirical work on EF includes measures of motor skills. Second, research that links early motor skills with later achievement either includes an observer-rated 
proxy for EF or does not consider EF at all. Third, measures of fine motor skills are typically an aggregate measure rather than separate component skills. Fourth, achievement outcomes are usually comprised of aggregated measures instead of separate skill components (e.g., phonological awareness, vocabulary). Fifth, prior work tends to evaluate achievement with a single assessment at a particular grade or chronological age, or a gain in achievement between two time points, but not both.

The present study incorporates a direct performance assessment for both EF and fine motor skills. It also includes a broad range of achievement outcome measures including composite measures of math, reading, and general knowledge as well as four subcomponents of reading including wordreading, comprehension, expressive vocabulary, and phonological awareness. Analyses provide estimates for predictors of achievement at kindergarten entrance as well as gains during kindergarten. Finally, three aspects of fine motor skills were measured including building with blocks, copying designs, and drawing a person. We hypothesized that both fine motor skills and EF would uniquely contribute to the range of achievement outcomes in fall and spring of kindergarten. Based on emerging neuroscientific evidence, we anticipated stronger links between fine motor, $\mathrm{EF}$, and mathematics achievement relative to reading outcomes. We also expected that when parsed from the other fine motor measures, design copy would be the relatively strongest predictor of achievement.

\section{Method}

Children and families in a suburban area of the Midwest were recruited to participate in a longitudinal study of the transition to school. Six preschools (five fee-based, one Head Start) housed within a single school district were contacted; recruitment of 3- and 4-year-olds occurred in the fall of 2002 and 2003 through parent orientations and backpack mailings. In 2002, about 200 families participated, and in 2003, an additional 150 families joined the study. In the fall of 2004, 50 families of select children, namely those from the Head Start site and siblings of participants, entered the study. Thus children came from three possible cohorts and had to turn either 3 or 4 years old by the December 1 state cutoff deadline.

Data from a total of 213 children (57\% Caucasian, 34\% multiracial, 4\% Asian, 3\% African American, $1 \%$ Hispanic, and 1\% Arabic) were used in the pres- ent study. Selection depended upon the availability of motor data prior to kindergarten entry and of EF and achievement outcomes in the fall and spring of kindergarten. The average education level of 188 mothers reporting was 16.2 years, or more than a college degree. Descriptive statistics and correlations among independent variables are shown in Tables 1 and 2. Correlations of independent variables with dependent variables are shown in Table 3.

\section{Procedure}

Data were used from three sources: a parent questionnaire, child assessments during a home visit, and individual child assessments at school. First, parents reported on characteristics of their family and participating child in a brief survey they received upon entering the study. Second, motor skills were assessed in a home visit conducted before children entered kindergarten. The visit lasted about $1.5 \mathrm{hr}$ and included other activities such as a parent-child book reading. Third, EF was measured in the fall of kindergarten, and achievement skills were measured in the fall and spring of kindergarten, in two 30-min batteries at the school.

Undergraduate and graduate students employed over the course of the longitudinal study were formally trained to administer all child assessments. First, they reviewed assessment materials and practiced administering each assessment to adults in the laboratory. Then they observed the assessment being given in the field, and finally they were observed by an expert assessor before being approved to assess children on their own. Reliability was adequate for all assessments and obtained by comparing average scores for each assessment across examiners (i.e., cross-examiner consistency; see also Cameron Ponitz et al., 2009); if there is no examiner bias, one would expect there to be no difference in average score according to examiner.

\section{Measures}

\section{Parent Questionnaire}

Parents reported on child gender, ethnicity, age, and level of education held by mothers. These variables were used as controls in analyses.

\section{Motor Skills}

Fine and gross motor skills were assessed with the Early Screening Inventory-Revised (ESI-R; Meisels, Marsden, Wiske, \& Henderson, 1997). Fine 
Table 1

Descriptive Statistics for All Variables

\begin{tabular}{|c|c|c|c|c|c|}
\hline & Time point & $n$ & $M(\%)$ & $S D$ & Range \\
\hline Male & - & 213 & $(47)$ & 0.50 & $0-1$ \\
\hline Non-Asian minority & - & 213 & (39) & 0.49 & $0-1$ \\
\hline Maternal education (years) & - & 188 & 16.15 & 1.77 & $10-18$ \\
\hline Achievement test age (years) & Fall & 213 & 5.44 & 0.33 & $4.64-6.21$ \\
\hline \multirow[t]{2}{*}{ Academic knowledge } & Fall & 213 & 466.31 & 12.02 & $437-495$ \\
\hline & Spring & 212 & 475.19 & 11.50 & $440-502$ \\
\hline \multirow[t]{2}{*}{ Applied problems } & Fall & 213 & 434.90 & 13.55 & $396-467$ \\
\hline & Spring & 212 & 446.36 & 14.86 & 413-485 \\
\hline \multirow[t]{2}{*}{ Reading composite } & Fall & 213 & 434.62 & 15.31 & $402.25-496.75$ \\
\hline & Spring & 212 & 452.12 & 16.76 & $416.25-503.25$ \\
\hline \multirow[t]{2}{*}{ Letter-word identification } & Fall & 213 & 376.63 & 28.92 & 305-508 \\
\hline & Spring & 212 & 409.02 & 29.74 & $348-515$ \\
\hline \multirow[t]{2}{*}{ Passage comprehension } & Fall & 213 & 411.78 & 21.81 & $377-494$ \\
\hline & Spring & 212 & 433.58 & 25.99 & $377-497$ \\
\hline \multirow[t]{2}{*}{ Picture vocabulary } & Fall & 213 & 479.20 & 10.23 & $448-513$ \\
\hline & Spring & 212 & 485.33 & 9.52 & $456-517$ \\
\hline \multirow[t]{2}{*}{ Sound awareness } & Fall & 213 & 470.86 & 12.76 & $427-505$ \\
\hline & Spring & 212 & 481.54 & 12.12 & $435-515$ \\
\hline HTKS-EF & Fall & 203 & 27.89 & 9.02 & $0-40$ \\
\hline Pre-kindergarten motor assessment age & - & 193 & 4.96 & 0.42 & $3.50-5.75$ \\
\hline Fine motor composite (mean) & - & 192 & 1.06 & 0.17 & $0.18-1.30$ \\
\hline Blocks (sum) & - & 190 & 4.47 & 0.84 & $1-5$ \\
\hline Design copy (sum) & - & 192 & 5.36 & 1.24 & $0-7$ \\
\hline Draw-a-person (single item) & - & 192 & 1.85 & 0.48 & $0-2$ \\
\hline Gross motor composite (sum) & - & 161 & 8.13 & 2.11 & $0-11$ \\
\hline
\end{tabular}

Note. HTKS-EF = Head-Toes-Knees-Shoulders executive function task.

Table 2

Correlations Among HTKS and Motor Predictor Variables $(\mathrm{n}=213$ )

\begin{tabular}{lccccccc}
\hline & 1 & 2 & 3 & 4 & 5 & 6 & 7 \\
\hline & - & .01 & $.15^{* *}$ & $.17^{* *}$ & .09 & .07 & .13 \\
1. HTKS-EF & - & $.31^{* *}$ & $.20^{* *}$ & $.23^{* *}$ & $.28^{* *}$ & $.38^{* *}$ \\
2. Motor assessment age & & & - & $.68^{* *}$ & $.86^{* *}$ & $.49^{* *}$ & $.32^{* *}$ \\
3. Fine motor composite & & & & - & $.32^{* *}$ & .13 & $.22^{* *}$ \\
4. Blocks & & & & & - & $.27^{* *}$ & $.24^{* *}$ \\
5. Design copy & & & & & - & $.28^{* *}$ \\
6. Draw-a-person & & & & & & - \\
7. Gross motor & & & & & & - \\
\hline
\end{tabular}

Note. HTKS-EF = Head-Toes-Knees-Shoulders executive function task.

${ }^{* *} p<.01$.

motor assessments consisted of 11 items that required manual dexterity and spatial organization. Items included building a tower, bridge, and gate with blocks (blocks); using a pencil to copy shapes pictured on cards such as a square or circle (design copy); and using a pencil and paper to draw a person from memory (draw-a-person). Except for bridge and draw-a-person, which were scored 0,1 , or 2 , all items were scored 0 if fail or 1 according to diagnostic criteria. The number of body parts determined the score of 0,1 , or 2 on draw-a-person. Additional scoring information is in the copyrighted manual, which provides examples and was used to score all assessments.

We created a single fine motor composite (mean) of all variables, plus three distinct variables: (a) three blocks items (sum), (b) seven design copy items (sum), and (c) the score on draw-a-person. A composite of six gross motor items (mean) scored 0, 1, and 2 was also used as a control. Gross motor items required children to balance and orient their body in space on tasks such as walking a line forward and backward, hopping on each foot, and skipping.

The ESI-R has demonstrated reliability and predictive validity for school performance through second grade (Meisels, Wiske, \& Tivnan, 1984). In this study, there were no significant examiner differences in obtained motor scores, $F(18,169)=1.27$, $p>.05$, suggesting adequate cross-examiner consistency. In addition, test-retest reliabilities for 186 children, with Time 2 administered 9-15 months after Time 1, were .60 for fine motor and .66 for gross motor skills. 


\section{Executive Function}

The Head-Toes-Knees-Shoulders (HTKS) structured observation of behavioral self-regulation was used to measure EF (Cameron Ponitz et al., 2009). Children were first told to follow the examiner's commands (e.g., touch your head) but then told to "be silly and do the opposite. If I say 'touch your head,' touch your toes instead." In Phase I, children were given several practice commands with feedback about two rules (e.g., head or toes) and then 10 test commands in a pseudorandom, fixed order. In Phase II, children were taught to follow two novel commands (e.g., knees or shoulders) and then do the opposite. After four practice commands with feedback, children were told they would hear one of four commands (touch your head or touch your toes; touch your knees or touch your shoulders) and should touch the "opposite" body part. Then they were given another 10 test commands with body parts fixed in a pseudorandom order.

The task requires children to pay attention to instructions, remember which body part goes with which for four different rules, and control their automatic tendency to touch the named part and instead touch a different part. Strong reliability and predictive validity have been demonstrated for the HTKS, which has 20 items scored 0,1 , or 2 (Cameron Ponitz et al., 2009; Matthews, Cameron Ponitz, \& Morrison, 2009). Reported correlations between the HTKS and individual EF components are around .20, including a standardized measure of auditory working memory (Burrage et al., 2008), and parent-rated inhibitory control and attentional focusing (Cameron Ponitz et al., 2009). The HTKS predicts academic achievement as well as teacherrated classroom behavior, indicating that it taps the executive processes associated with success in educational settings, our present focus (Matthews et al., 2009). In this study, there were no examiner differences in average scores obtained on the task, $F(12,184)=0.98, p=.47$.

\section{Kindergarten Achievement}

$W$-scores on six subtests from the WoodcockJohnson III (WJ III) Tests of Achievement were used as outcome variables (Woodcock, McGrew, \& Mather, 2001). Split-half reliability coefficients with North American 5-year-olds range from .76 to .99 (Mather \& Woodcock, 2001). On 12 tests (6 each at fall and spring), there were significant differences in average score obtained by examiner for only one subtest (fall academic knowledge), $F(12,212)=1.86, p<.05$, or 92\% cross-examiner consistency. Testing stopped after three or six incorrect responses, depending on the subtest. The final four subtests (word-reading, passage comprehension, picture vocabulary, and sound awareness) were also examined as an overall mean reading composite.

General knowledge. General knowledge was measured using a composite score from WJ III academic knowledge, which includes three subtests: Social studies asked children about the social world and community with questions like "Who delivers the mail?" and "What is this?" about a picture of a school. Science included questions about the natural world, such as "What sound follows lightning?" and "What animal is this?" Humanities included questions from popular literature and culture such as "What musical instrument is this?" and "finish this sentence: 'once upon a __.'"

Mathematics. The applied problems subtest used pictures of objects and symbols to measure children's early mathematics skills. Children answered questions such as "If I took away two balloons, how many would I have left?" and "What time does this clock say?"

Word-reading. In letter-word identification, used to measure word-reading, children identified lowercase and uppercase letters, and then read actual words of increasing difficulty.

Reading comprehension. In passage comprehension, children were asked to select a symbol or word on a cloze task. For example, children pointed to the symbol, such as a stick figure versus a symbol of a house or a cat, that matched a realistic picture of a person. As the task progressed in difficulty, children read a sentence missing a word and stated the word that best completed the sentence.

Vocabulary. The WJ III subtest of picture vocabulary was used to measure expressive vocabulary. Children were asked to name pictured objects, such as buildings, animals, and tools.

Phonological awareness. Children's knowledge of the sounds comprising words was measured using a composite score from four subtests from WJ III sound awareness. Part A focused on rhyme, such as identifying two rhyming words of three options. Part B required syllabic and phonemic deletion, such as saying "football" without the word "foot." Part C tested substitution, such as changing the /sh/ sound in "shoe" to $/ \mathrm{t} /$. Part $\mathrm{D}$ required children to reverse syllable and phonemes, such as saying football backward (ball, foot) or reversing the phonemes in "pat" to say "tap." 


\section{Analytic Strategy}

Gender, ethnicity, age, and maternal education were held constant to examine the unique contributions of EF and fine motor skills to kindergarten entry performance and achievement across the school year. Based on the relatively small amount of missing data (see Table 1), Mplus (Muthén \& Muthén, 2009) full information maximum likelihood (FIML) estimation was used. FIML uses all available data to estimate parameters, and thus, all 213 children in the sample were retained in analyses (Schafer \& Graham, 2002). First we examined descriptive statistics (see Table 1), correlations among EF and motor predictors (see Table 2), and correlations among predictor and outcome variables (see Table 3).

For the research aims, multilevel modeling was used to address the violation of independence assumption for the 213 children nested in 81 classrooms. That is, of the 12 outcomes (six achievement scores at fall and spring), the classroom-level variance or intraclass correlation was significantly different from zero for fall applied problems (with $12 \%$ of the variance at the classroom level) and fall sound awareness (9\%); spring letter-word identification (15\%), spring passage comprehension (16\%), and spring sound awareness (11\%). Equations for a generic model including fall scores are described in the Appendix.

With fall and spring outcomes for academic knowledge, applied problems, and the reading composite, plus four individual language and literacy subtests, there were 14 total outcome variables. For each outcome, three types of models were first examined: (1a) separate entry: HTKS-EF and (1b) separate entry: fine motor composite; (2) simultaneous entry: HTKS-EF and fine motor composite; and (3) individual fine motor predictors. The predictors entered in each of these models are shown in Table 4. For parsimony, $t$ values for HTKS-EF and motor predictors for the three types of models are summarized for comparative purposes in Table 5 for all 14 outcomes. This enables the reader to discern the magnitude of changes in the HTKS-EF and fine motor composite $t$ values with the alternate predictor included. If $t$ values for the simultaneous entry models are similar to those in the separate entry models, this provides evidence that HTKS-EF and fine motor skills make distinct contributions to achievement.

\section{Results}

Descriptive statistics and correlations among the predictor and outcome variables were first examined.

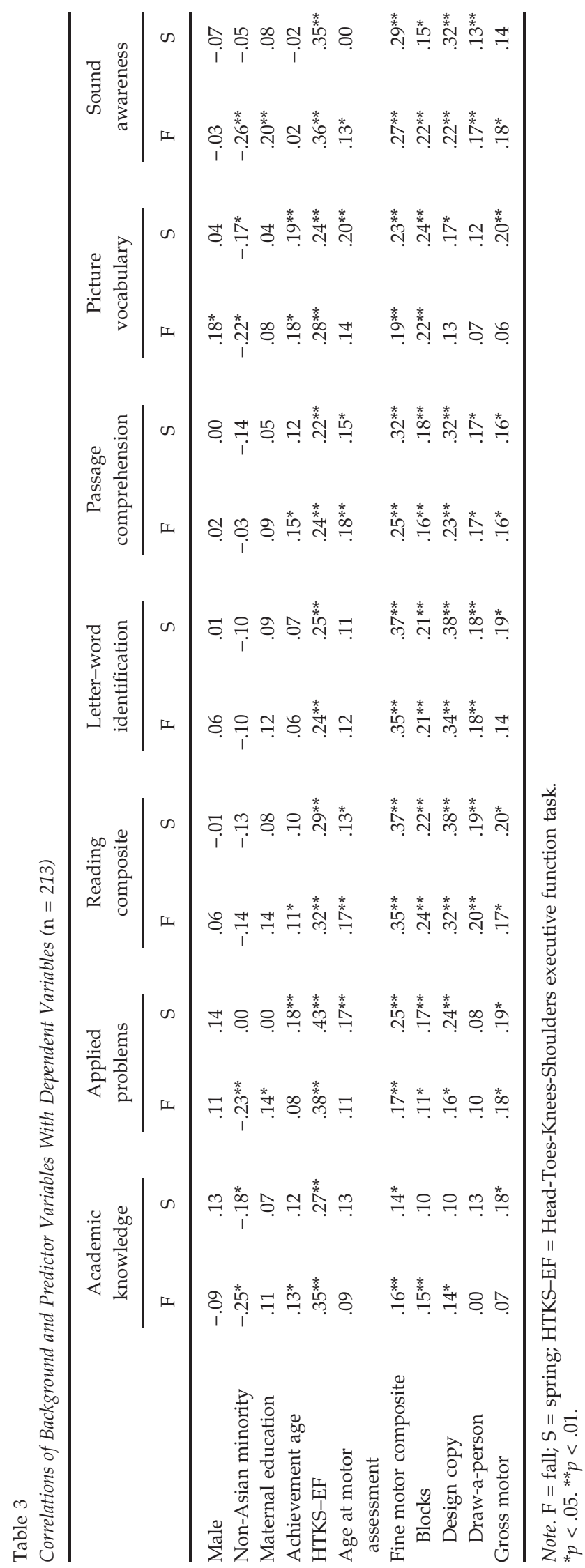


Table 4

Models for Each Achievement Outcome

\begin{tabular}{lcccc}
\hline Predictor & $\begin{array}{c}\text { (1a) Separate } \\
\text { entry: HTKS-EF }\end{array}$ & $\begin{array}{c}\text { (1b) Separate entry: } \\
\text { fine motor composite }\end{array}$ & $\begin{array}{c}\text { (2) Simultaneous } \\
\text { entry }\end{array}$ & $\begin{array}{c}\text { (3) Individual fine } \\
\text { motor predictors }\end{array}$ \\
\hline Achievement test age & $\mathrm{X}$ & $\mathrm{X}$ & $\mathrm{X}$ & $\mathrm{X}$ \\
Male & $\mathrm{X}$ & $\mathrm{X}$ & $\mathrm{X}$ & $\mathrm{X}$ \\
Non-Asian minority & $\mathrm{X}$ & $\mathrm{X}$ & $\mathrm{X}$ & $\mathrm{X}$ \\
Maternal education & $\mathrm{X}$ & $\mathrm{X}$ & $\mathrm{X}$ \\
HTKS-EF & $\mathrm{X}$ & $\mathrm{X}$ & $\mathrm{X}$ \\
Age at motor test & & $\mathrm{X}$ & $\mathrm{X}$ & \\
Fine motor composite & & & $\mathrm{X}$ \\
Blocks & & & $\mathrm{X}$ \\
Design copy & & $\mathrm{X}$ & \\
Draw-a-person & & & $\mathrm{X}$ \\
Gross motor composite & & & \\
\hline
\end{tabular}

Note. All models included control variables. (a1) Models added fall score for spring achievement outcomes and HTKS-EF. (a2) Models added the fine motor composite and motor control variables (age at motor assessment and gross motor composite). (b) Models added $\mathrm{EF}$ and the fine motor composite and associated variables, entered simultaneously. (c) Models replaced the fine motor composite with individual fine motor predictor variables (blocks, design copy, and draw-a-person). HTKS-EF = Head-Toes-Knees-Shoulders executive function task.

Table 5

T-Value Comparison for Models With HTKS-EF and Fine Motor Composite Entered Separately, Simultaneously, and With Individual Fine Motor Predictors $(\mathrm{n}=213)$

\begin{tabular}{|c|c|c|c|c|c|c|c|c|}
\hline & \multicolumn{2}{|c|}{ (1) Separate entry } & \multicolumn{2}{|c|}{ (2) Simultaneous entry } & \multicolumn{4}{|c|}{ (3) Individual fine motor predictors } \\
\hline & HTKS-EF only & $\begin{array}{l}\text { Fine motor } \\
\text { composite only }\end{array}$ & $\begin{array}{l}\text { HTKS-EF (with fine } \\
\text { motor composite) }\end{array}$ & $\begin{array}{l}\text { Fine motor composite } \\
\text { (with HTKS-EF) }\end{array}$ & HTKS-EF & Blocks & $\begin{array}{l}\text { Design } \\
\text { copy }\end{array}$ & $\begin{array}{l}\text { Draw-a- } \\
\text { person }\end{array}$ \\
\hline \multicolumn{9}{|c|}{ Academic knowledge } \\
\hline Fall & 5.12 & 2.79 & 4.69 & 2.09 & 4.65 & 1.23 & 1.88 & -1.09 \\
\hline Fall-spring & 1.01 & -0.33 & 0.90 & -0.47 & 0.85 & -0.32 & -0.73 & 1.87 \\
\hline \multicolumn{9}{|c|}{ Applied problems } \\
\hline Fall & 5.16 & 1.76 & 5.06 & 1.00 & 5.14 & -0.37 & 1.58 & 0.55 \\
\hline Fall-spring & 4.52 & 1.83 & 4.34 & 1.39 & 4.45 & 0.29 & 1.84 & -0.49 \\
\hline \multicolumn{9}{|c|}{ Reading composite } \\
\hline Fall & 4.93 & 3.92 & 5.10 & 3.69 & 5.04 & 0.90 & 3.80 & 1.04 \\
\hline Fall-spring & 0.65 & 2.3 & 0.28 & 2.24 & 0.36 & 0.08 & 2.70 & 0.03 \\
\hline \multicolumn{9}{|l|}{ Letter-word ID } \\
\hline Fall & 3.29 & 4.07 & 3.28 & 4.06 & 3.23 & 0.74 & 3.92 & 0.92 \\
\hline Fall-spring & 0.95 & 1.88 & 0.68 & 1.80 & 0.74 & 0.04 & 1.98 & -0.06 \\
\hline \multicolumn{9}{|c|}{ Passage comprehension } \\
\hline Fall & 3.38 & 2.64 & 3.42 & 2.38 & 3.38 & 0.41 & 2.04 & 1.23 \\
\hline Fall-spring & 1.26 & 3.25 & 0.88 & 3.13 & 0.94 & 0.67 & 3.69 & 0.54 \\
\hline \multicolumn{9}{|c|}{ Picture vocabulary } \\
\hline Fall & 4.30 & 3.39 & 3.64 & 2.62 & 3.47 & 1.63 & 1.05 & 0.87 \\
\hline Fall-spring & 1.26 & 1.51 & 0.93 & 1.32 & 0.93 & 1.57 & 0.65 & 0.86 \\
\hline \multicolumn{9}{|c|}{ Sound awareness } \\
\hline Fall & 5.14 & 2.74 & 4.76 & 2.24 & 4.68 & 0.94 & 2.11 & 0.48 \\
\hline Fall-spring & 2.42 & 2.37 & 1.84 & 2.21 & 2.10 & -1.03 & 3.09 & 0.19 \\
\hline
\end{tabular}

Note. All $t$ values are from models controlling for background variables (male gender, non-Asian minority, maternal education, and achievement test age). Fall-spring models also control for fall achievement score. HTKS-EF = Head-Toes-Knees-Shoulders executive function task. 
Children were on average 5 years old at the motor assessment, 5.4 years at the fall HTKS-EF and achievement assessments, and 5.9 years at the spring assessment. All participants received the motor assessment before being tested for achievement; however, there was variation around the mean age at motor assessment (range $=3.50-5.75$ years). Based on this variation, age at motor assessment was entered as an additional control. Scores for HTKS$\mathrm{EF}$ and the motor predictors showed variability, with some ceiling effects. For HTKS-EF, the mean score was 27.9 of 40 points (3\% at ceiling). On average, children scored 4.5 of 5 points (65\% at ceiling) on blocks, 5.4 of 7 points ( $20 \%$ at ceiling) on design copy, and 1.9 of 2 points ( $90 \%$ at ceiling) on draw-aperson. On the gross motor composite, children earned, on average, 8.1 of 11 possible points (15\% at ceiling).

Table 2 shows correlations among individual predictor variables. HTKS-EF was positively correlated with the fine motor composite and blocks, but not design copy or draw-a-person. Children who were older at the motor assessment had higher motor scores. In addition, children with stronger scores on one motor predictor tended to score higher on the other motor predictors, but correlations were surprisingly modest. Table 3 includes correlations of HTKS-EF and motor predictors with achievement outcomes, indicating positive correlations among HTKS-EF and achievement outcomes, and among motor predictors and achievement outcomes. These positive correlations encourage further analyses to address whether motor skills and achievement are related due to shared variance among motor skills and HTKS-EF.

\section{Do EF and Fine Motor Both Predict Kindergarten Entry Achievement?}

First we examined whether fine motor predicted kindergarten fall achievement, after controlling for background variables and HTKS-EF. Consistent with hypotheses, kindergarteners with higher fine motor composite scores achieved at higher levels on the fall outcomes, with the exception of applied problems. The $t$ values for HTKS-EF remained similar with the fine motor composite included, suggesting that HTKS-EF and fine motor contributed separately to fall kindergarten achievement (see Table 5, columns 1a and 2). This was confirmed by examining the models under $1 b$, which included the fine motor composite but not HTKSEF. Looking across columns $1 \mathrm{a}, 1 \mathrm{~b}$, and 2, the $t$ values for HTKS-EF and the fine motor composite were markedly similar regardless of whether they were entered as separate or simultaneous predictors, lending support to the hypothesis that each made distinct contributions to fall achievement.

Complete results for individual motor predictor models are reported in Table 6 (fall achievement) and Table 7 (fall-spring improvement). Table 8 shows random effects from incremental models for individual outcome variables with individual motor predictors. Incremental models allow the percent of

Table 6

Fixed Effects Estimates From Models With Motor Skills and EF Predicting Fall Kindergarten Achievement $(\mathrm{n}=213)$

\begin{tabular}{|c|c|c|c|c|c|c|c|c|c|c|c|c|}
\hline & \multicolumn{2}{|c|}{$\begin{array}{l}\text { Academic } \\
\text { knowledge }\end{array}$} & \multicolumn{2}{|c|}{$\begin{array}{l}\text { Applied } \\
\text { problems }\end{array}$} & \multicolumn{2}{|c|}{$\begin{array}{l}\text { Letter-word } \\
\text { identification }\end{array}$} & \multicolumn{2}{|c|}{$\begin{array}{c}\text { Passage } \\
\text { comprehension }\end{array}$} & \multicolumn{2}{|c|}{$\begin{array}{c}\text { Picture } \\
\text { vocabulary }\end{array}$} & \multicolumn{2}{|c|}{$\begin{array}{c}\text { Sound } \\
\text { awareness }\end{array}$} \\
\hline & Coeff. & $t$ & Coeff. & $t$ & Coeff. & $t$ & Coeff. & $t$ & Coeff. & $t$ & Coeff. & $t$ \\
\hline Intercept & 467.33 & 442.03 & 432.87 & 357.25 & 373.58 & 139.52 & 410.59 & 205.17 & 477.87 & 579.27 & 470.66 & 440.02 \\
\hline Age & 4.74 & 1.44 & -2.46 & -0.51 & 2.30 & 0.30 & 5.88 & 0.99 & 5.05 & $1.69^{\dagger}$ & -4.95 & -1.17 \\
\hline Male & -2.14 & -1 & 4.12 & $2.33^{*}$ & 5.80 & 1.26 & 2.58 & 0.81 & 2.86 & $1.93^{*}$ & 0.38 & 0.25 \\
\hline Non-Asian minority & -4.39 & $-3.08^{* *}$ & -3.49 & $-1.99 *$ & -3.77 & -1.06 & 0.37 & 0.13 & -2.99 & $-2.45^{*}$ & -5.00 & $-3.31^{* *}$ \\
\hline Maternal education & 0.41 & 0.88 & 0.43 & 0.73 & 1.06 & 1.05 & 0.60 & 0.81 & 0.19 & 0.44 & 0.79 & 1.45 \\
\hline HTKS-EF & 0.39 & $4.65^{* *}$ & 0.52 & $5.14^{* *}$ & 0.63 & $3.23^{* *}$ & 0.48 & $3.38^{* *}$ & 0.26 & $3.47^{* *}$ & 0.42 & $4.68^{* *}$ \\
\hline Motor age & -0.46 & -0.16 & 2.00 & 0.48 & -0.60 & -0.08 & 1.67 & 0.30 & -1.20 & -0.47 & 4.00 & 1.11 \\
\hline Blocks & 1.30 & 1.23 & -0.49 & -0.37 & 2.20 & 0.74 & 1.05 & 0.41 & 1.96 & $1.63^{\dagger}$ & 1.22 & 0.94 \\
\hline Design copy & 1.25 & $1.88^{\dagger}$ & 1.08 & 1.58 & 6.75 & $3.92^{* *}$ & 2.79 & $2.04^{*}$ & 0.69 & 1.05 & 1.37 & $2.11^{*}$ \\
\hline Draw-a-person & -1.58 & -1.09 & 1.17 & 0.55 & 4.98 & 0.92 & 3.75 & 1.23 & 1.18 & 0.87 & 1.16 & 0.48 \\
\hline Gross motor & -0.33 & -0.79 & 0.68 & 1.28 & 0.07 & 0.06 & 0.44 & 0.54 & -0.25 & -0.63 & 0.17 & 0.44 \\
\hline
\end{tabular}

Note. All intercept estimates are significantly different from zero at $p<.01 . \mathrm{EF}=$ executive function; Coeff. $=$ coefficient; HTKS-EF $=$ Head-Toes-Knees-Shoulders EF task.

${ }^{\dagger} p<.10 .{ }^{*} p<.05 .{ }^{* *} p<.01$. 
Fixed Effects Estimates From Models With Motor Skills and EF Predicting Fall-Spring Improvement ( $\mathrm{n}=213)$

\begin{tabular}{|c|c|c|c|c|c|c|c|c|c|c|c|c|}
\hline & \multicolumn{2}{|c|}{$\begin{array}{l}\text { Academic } \\
\text { knowledge }\end{array}$} & \multicolumn{2}{|c|}{$\begin{array}{l}\text { Applied } \\
\text { problems }\end{array}$} & \multicolumn{2}{|c|}{$\begin{array}{l}\text { Letter-word } \\
\text { identification }\end{array}$} & \multicolumn{2}{|c|}{$\begin{array}{c}\text { Passage } \\
\text { comprehension }\end{array}$} & \multicolumn{2}{|c|}{$\begin{array}{c}\text { Picture } \\
\text { vocabulary }\end{array}$} & \multicolumn{2}{|c|}{ Sound awareness } \\
\hline & Coeff. & $t$ & Coeff. & $t$ & Coeff. & $t$ & Coeff. & $t$ & Coeff. & $t$ & Coeff. & $t$ \\
\hline Intercept & 475.60 & 551.36 & 445.14 & 430.65 & 408.46 & 265.31 & 433.08 & 221.17 & 485.23 & 623.15 & 481.56 & 583.02 \\
\hline Age & -1.04 & -0.44 & 4.19 & 1.17 & 3.90 & 0.88 & 3.30 & 0.48 & 2.64 & 0.97 & 2.69 & 0.80 \\
\hline Male & -1.03 & -0.92 & 2.66 & $2.00^{*}$ & -1.48 & -0.69 & -0.44 & -0.16 & -1.07 & -1.07 & -0.03 & -0.02 \\
\hline Non-Asian minority & 0.26 & 0.20 & 2.95 & $2.00^{* *}$ & -0.98 & -0.42 & -5.63 & $-2.27^{*}$ & -0.74 & -0.70 & 2.14 & $1.74^{\dagger}$ \\
\hline Maternal education & -0.19 & -0.48 & -0.71 & -1.52 & -0.56 & -0.91 & -0.53 & -0.71 & -0.01 & -0.04 & -0.40 & -1.13 \\
\hline Fall score & 0.63 & $11.93^{* *}$ & 0.58 & $9.43^{* *}$ & 0.84 & $23.83^{* *}$ & 0.68 & $10.11^{* *}$ & 0.52 & $9.42^{* *}$ & 0.62 & $9.20^{* *}$ \\
\hline HTKS-EF & 0.07 & 0.85 & 0.42 & $4.45^{* *}$ & 0.09 & 0.74 & 0.16 & 0.94 & 0.06 & 0.93 & 0.16 & $2.10^{*}$ \\
\hline Motor age & 1.17 & 0.57 & 0.64 & 0.23 & -4.15 & -1.04 & -3.69 & -0.61 & 0.00 & 0.00 & -4.80 & -1.52 \\
\hline Blocks & -0.27 & -0.32 & 0.44 & 0.29 & 0.06 & 0.04 & 1.27 & 0.67 & 1.08 & 1.57 & -0.72 & -1.03 \\
\hline Design copy & -0.40 & -0.73 & 1.25 & $1.84^{\dagger}$ & 2.01 & $1.98^{*}$ & 3.47 & $3.69^{* *}$ & 0.33 & 0.65 & 1.81 & $3.09^{* *}$ \\
\hline Draw-a-person & 1.86 & $1.87^{\dagger}$ & -1.01 & -0.49 & -0.12 & -0.06 & 1.51 & 0.54 & 0.20 & 0.86 & 0.29 & 0.19 \\
\hline Gross motor & 0.55 & $1.82^{\dagger}$ & 0.43 & 0.98 & 0.74 & 1.23 & 0.11 & 0.13 & 0.31 & 1.02 & 0.14 & 0.35 \\
\hline
\end{tabular}

Note. All intercept estimates are significantly different from zero at $p<.01$. EF $=$ executive function; Coeff. = coefficient; HTKS$\mathrm{EF}=$ Head-Toes-Knees-Shoulders EF task.

${ }^{\dagger} p<.10 .{ }^{*} p<.05 .{ }^{* *} p<.01$.

variance explained by key predictor variables to be calculated, similar to hierarchical regression. In addition, for fall outcomes, the number of points associated with a $1 S D$ increase in key predictors was calculated. Based on this, HTKS-EF explained $4 \%-17 \%$ of the variance in each fall achievement outcome (see Table 8). Holding other variables constant at their mean, children who scored $1 S D$ above the mean HTKS-EF, or 37 instead of 28 points, scored between a minimum of 2.4 points (picture vocabulary) and a maximum of 5.8 points (letter-word identification) above the mean on fall achievement tests.

In addition, design copy predicted three achievement outcomes: For letter-word identification, a score of $1 S D$ above the mean design copy score, or a score of 6.6 instead of 5.4, was associated with children scoring 8.4 points higher than the mean letter-word identification score $(11 \%$ variance explained), 3.5 points above the mean on passage comprehension (4\% variance explained), and 1.7 points above the mean on sound awareness $(6 \%$ variance explained).

\section{Do EF and Fine Motor Both Predict Fall-Spring Improvement?}

Models for fall-spring improvement showed that children's fall score was the best predictor of their spring achievement, which is unsurprising given the stability of standardized achievement test scores over time (Curby, Rimm-Kaufman, \& Cameron Ponitz, 2009). In contrast with fall model results where HTKS-EF significantly predicted all outcomes, $t$ values for HTKS-EF reached statistical significance for fall-spring improvement in only two of six outcomes (applied problems and sound awareness; see Table 7). HTKS-EF explained 5\% of the variance in applied problems and 1\% of the variance in sound awareness. Like the fall results, HTKS-EF $t$ values did not change drastically with fine motor predictors included, indicating that HTKS-EF and fine motor made separate contributions to fall-spring improvement (see Table 5). Also similar to the fall results, $t$ values for the fine motor composite entered without HTKS-EF were highly similar to the $t$ values for the fine motor composite entered with HTKS-EF.

Table 7 shows fixed effects for the full models of fall-spring improvement. Children with strong fine motor skills improved more from fall-spring in the reading composite compared to children with weak motor skills; within the reading composite, strong fine motor skills predicted significantly greater gains in passage comprehension and sound awareness, and letter-word identification at a level of marginal significance. Specifically, higher design copy performance significantly predicted greater fall-spring improvement in letter-word identification (1\% of unique variance explained).

For fall-spring improvement, the number of weeks of learning associated with a $1 S D$ increase 


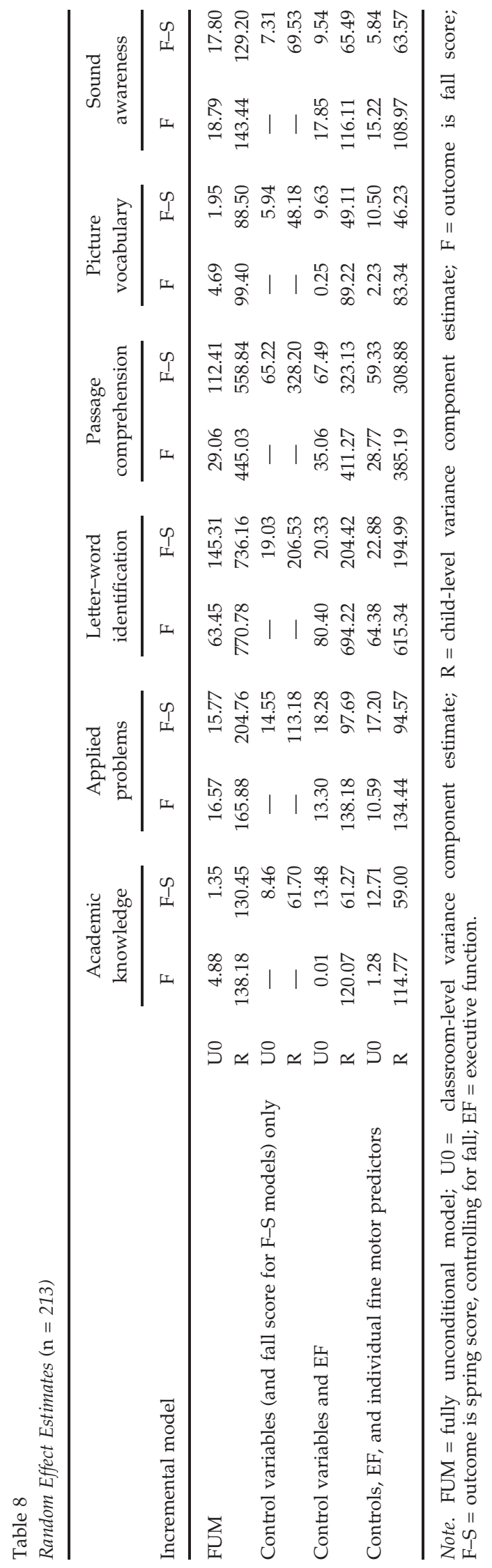

in key predictors was calculated. This was performed using the average number of points gained per month in each outcome [(spring score - fall score)/6-month test interval]. In practical terms, a score of 6.6 instead of the average 5.4 on design copy was associated with children making 1.9 weeks of additional progress on letter-word identification. A $1 S D$ increase on design copy was associated with children being 4.7 weeks ahead of their peers on passage comprehension ( $4 \%$ variance explained). Finally, children who were $1 S D$ ahead of peers on design copy made 5 additional weeks of gain on sound awareness (3\% variance explained).

No other motor predictor was significant at $p<.05$, although higher scores on both draw-a-person and gross motor skills predicted greater fall-tospring improvement in academic knowledge at the marginally significant level.

\section{Post Hoc Analyses: Are Results Due to Low Scorers?}

In a post hoc analysis, we considered whether results were being driven by a small group of children with low scores on either predictor of interest. To address this possibility, we analyzed the final models after excluding $41(20 \%)$ of children who scored below 20 of 40 points on HTKS-EF. A score above 20 points corresponds to the phase of the HTKS-EF where demands increased from two rules to four rules to remember. Results for fine motor remained essentially the same, whereas fall HTKS-EF predicted only applied problems and academic knowledge in the fall, and did not significantly predict fall-spring improvement in any achievement subtest. We also ran analyses that excluded children who scored more than $1 S D$ below the mean on design copy (below 4 of 7 points; $n=61$ or $29 \%$ ). The pattern of results for design copy was the same or stronger than with all 213 children.

\section{Discussion}

This study examines the contributions of EF and fine motor skills to kindergarten achievement, and includes analyses with three individual fine motor predictors that have traditionally been combined (blocks, design copy, and draw-a-person). Analyses indicate that EF and fine motor skills make independent contributions to children's entry-level achievement as well as improvement from fall to spring of kindergarten. In particular, strong design 
copy performance tends to be associated with gains in literacy-related domains. This study extends other work that has employed only teacher reports of EF-related classroom behavior or that has examined motor and EF together in clinical but not normative populations.

A distinguishing feature of the present study is that motor and EF skills were assessed in a sample of socioeconomically advantaged children, with the finding that fine motor scores fall along a continuum and predict kindergarten entry performance and fall-spring learning. In support of this claim, when children with low scores on design copy are removed, design copy predicts all outcomes except fall-spring improvement in letterword identification, plus two additional outcomes (fall applied problems and fall-spring picture vocabulary) across the full range of scores. This suggests that the relevance of the design copy task for achievement extends beyond the subgroup of children with the most difficulty performing the task. In contrast, EF results are attenuated when removing the $20 \%$ of children with the lowest HTKS scores.

\section{EF Predicts Kindergarten Readiness When Motor Skills Are Also Considered}

The pattern of findings where EF predicts all six kindergarten entry achievement tests corroborates a large body of literature that illuminates EF as an important indicator of school readiness (Duncan et al., 2007; Mazzocco \& Kover, 2007; Morrison et al., 2010). EF is implicated in problem solving, which requires the recall and coordination of information in novel ways, and in learning-related behaviors relevant in the classroom, including following directions and sustaining attention (Zelazo, Carter, Reznick, \& Frye, 1997). These same skills would also benefit children during a direct assessment on a battery of tests. Even with fine motor skills controlled, EF significantly predicts all six academic achievement measures in the fall of kindergarten, which is not surprising given the relatively modest correlation among EF and all of the motor measures. However, EF predicts fallspring improvement in only two outcomes: mathematics and phonological awareness. These two domains (or WJ subtests) may have relatively heightened spontaneous problem-solving demands. For example, doing mathematics requires maintaining and manipulating individual numbers in mind to produce an answer that involves all the numbers; similarly, phonological awareness means putting several sounds together to form a single word (e.g., say $t / a / p$ backward to make a new word). In contrast, improvement in general knowledge, decoding, vocabulary, and comprehension in kindergarten may not depend as heavily on EF components (see also Cameron Ponitz et al., 2009).

\section{Design Copy Predicts Learning Gains When EF Is Also Considered}

Relative to EF, fine motor skills, particularly children's ability to copy designs, is more strongly associated with fall-spring gains in decoding, reading comprehension, and overall reading. Like EF, design copy performance also significantly predicts gains in phonological awareness and marginally predicts mathematics. These findings may be understood in the context of work on the competing motor and cognitive demands of any given task. Children who enter kindergarten having already learned to copy forms and write letters can deploy their attention to learning more complex literacy skills such as reading words and sentences. That is, the extent to which a child can achieve automaticity with writing-related tasks may determine the amount of cognitive capacity he or she is able to focus on other learning objectives (Medwell, Strand, \& Wray, 2007). In contrast, children who struggle to hold a pencil and who must attend to the specific movements that are needed to form letters will not be able to progress as quickly in the cognitive tasks of decoding longer words, reading for comprehension, and connecting letters with their sounds. In line with this interpretation, prior evidence shows that kindergarteners' ability to reproduce letters is related to teachers' ratings of their literacy, vocabulary, and mathematics skills in first grade (Simner, 1982). Children with strong design copy skills may learn numbers and letters and complete basic classroom tasks faster than children with weak copy skills, which may in turn support their ability to learn to read, manipulate the sounds within words, and perform simple arithmetic during the kindergarten year.

In addition to signaling automaticity in writing, design copy may indicate facility in underlying, as-yet-unknown cognitive processes that are foundational to learning (Stanovich, 2008). Other research identifies copying designs as distinct from other fine motor tasks (e.g., tracing; Bremner \& Morse, 2000) because it requires children to process visual information from an external stimulus, invoke a mental representation, and coordinate motor movements to reproduce the image. The 
draw-a-person task also requires mental representation, but this representation does not need to match anything in the outside world. Notably, design copy does not predict general knowledge or expressive vocabulary, which both depend upon children's recall of acquired, distinct pieces of information. Previous research has shown that crystallized intelligence and fine motor skills are distinct (Nijenhuis \& van der Flier, 2002).

\section{Limitations}

This study has some limitations. First, it does not address causality or underlying mechanisms, nor does it consider a possible reciprocal association between fine motor skills and achievement, where achievement may boost fine motor skills (Zelazo, 1984). Although design copy skills may be a precursor to achievement gains in kindergarten, this does not preclude alternative pathways to learning, which are evident in studies of physically disabled children who nonetheless achieve on par with typically developing peers (Rivière, Lécuyer, \& Hickmann, 2009). Second, the lack of association among blocks, draw-a-person, and achievement may derive partially from ceiling effects on those two fine motor tasks. Other studies have found a significant relation between block building (Wolfgang, Stannard, \& Jones, 2003), draw-a-person (Stevenson \& Newman, 1986), and achievement, but did not concurrently assess multiple fine motor skills or EF. To clarify the role of other fine motor components beyond design copy as potential predictors of achievement, future work could employ measures of multiple fine motor tasks that demonstrate adequate variability. A third limitation is that it would have been ideal to assess motor skills immediately prior to the fall achievement tests rather than at varying ages before kindergarten entry.

\section{Implications and Future Directions}

This study has both scientific and practical implications. Future research can begin to unpack the nature of the relation between fine motor skills and academic achievement by exploring causality, reciprocity, and exceptionality. Particularly important will be efforts to describe what distinguishes the various tasks used to assess fine motor skills, to determine what aspects of these tasks are most closely related to achievement, and to identify how and when this relation emerges (Stanovich, 2008). The theoretical issues related to motor skills need to be evaluated and possibly refined (Burton \&
Rodgerson, 2001). At present, the term fine motor is a catch-all label for a variety of skills with distinct processing demands, including copying designs from an external stimulus and generating forms from memory, in either two or three dimensions. Our study indicates that these skills predict achievement separately from EF, even when children with the lowest design copy skills are excluded from the analysis. Theoretical efforts to clarify such concepts would inform practical work that seeks to identify and intervene on the specific skills children need most to succeed in school.

This study's results highlight motor development as a contributor to kindergarten entry performance and children's learning over the year in a variety of domains. Fine motor skills are a prominent part of what kindergarten teachers ask children to do, but wide variation has been observed in students' experiences with motor activities (Marr et al., 2003). Furthermore, gaps in motor skill can be traced to sociodemographic factors such as gender, ethnicity, and socioeconomic status, and indicate that although some children enter the kindergarten classroom well prepared to do motor tasks, others do not (Grissmer \& Eiseman, 2008). Increasing children's opportunities for fine motor learning experiences with elements of design copy may be one direction for curriculum supplements in early childhood, which has been identified as the most economically efficient period of human development for intervention (Heckman et al., 2006).

\section{References}

Bart, O., Hajami, D., \& Bar-Haim, Y. (2007). Predicting school adjustment from motor abilities in kindergarten. Infant \& Child Development, 16, 597-615.

Berger, S. E. (2010). Locomotor expertise predicts infants' perseverative errors. Developmental Psychology, 46, 326336.

Best, J. R., \& Miller, P. H. (2010). A developmental perspective on executive function. Child Development, 81, 1641-1660.

Boudreau, J. P., \& Bushnell, E. W. (2000). Spilling thoughts: Configuring attentional resources in infants' goal-directed actions. Infant Behavior \& Development, 23, 543-566.

Bredekamp, S., \& Copple, C. (1997). Developmentally appropriate practice in early childhood programs. Washington, DC: National Association for the Education of Young Children.

Bremner, J. G., \& Morse, R. (2000). Relations between drawing cubes and copying line diagrams of cubes in 7- to 10-year-old children. Child Development, 71, 621. 
Brooks, R., \& Goldstein, S. (2007). Raising a self-disciplined child: Help your child become more responsible, confident, and resilient. New York: McGraw-Hill.

Burrage, M. S., Cameron Ponitz, C., McCready, E. A., Shah, P., Sims, B. C., Jewkes, A. M., et al. (2008). Ageand schooling-related effects on executive functions in young children: A natural experiment. Child Neuropsychology, 14, 510-524.

Burton, A. W., \& Rodgerson, R. W. (2001). New perspectives on the assessment of movement skills and motor abilities. Adapted Physical Activity Quarterly, 18, 347-365.

Cameron Ponitz, C., McClelland, M. M., Matthews, J. S., \& Morrison, F. J. (2009). A structured observation of behavioral self-regulation and its contribution to kindergarten outcomes. Developmental Psychology, 45, 605-619.

Campos, J. J., Kermoian, R., \& Zumbahlen, M. R. (1992). Socioemotional transformations in the family system following infant crawling onset. In N. Eisenberg \& R. A. Fabes (Eds.), Emotion and its regulation in early development (pp. 25-40). San Francisco: Jossey-Bass.

Chappell, P. A., \& Steitz, J. A. (1993). Young children's human figure drawings and cognitive development. Perceptual and Motor Skills, 76, 611-617.

Curby, T. W., Rimm-Kaufman, S. E., \& Cameron Ponitz, C. (2009). Teacher-child interactions and children's achievement trajectories across kindergarten and first grade. Journal of Educational Psychology, 101, 912-925.

Daly, C. J., Kelley, G. T., \& Krauss, A. (2003). Relationship between visual-motor integration and handwriting skills of children in kindergarten: A modified replication study. American Journal of Occupational Therapy, 57, 459-462.

Diamond, A. (2000). Close interrelation of motor development and cognitive development and of the cerebellum and prefrontal cortex. Child Development, 71, 44-56.

Duckworth, A. L., \& Seligman, M. E. P. (2005). Self-discipline outdoes IQ in predicting academic performance of adolescents. Psychological Science, 16, 939-944.

Duncan, G. J., Dowsett, C. J., Claessens, A., Magnuson, K., Huston, A. C., Klebanov, P., et al. (2007). School readiness and later achievement. Developmental Psychology, 43, 1428-1446.

Entwisle, D. R., Alexander, K. L., \& Olson, L. S. (2005). First grade and educational attainment by age 22: A new story. American Journal of Sociology, 110, 1458-1502.

Grissmer, D., \& Eiseman, E. (2008). Can gaps in the quality of early environments and non-cognitive skills help explain persisting Black-White achievement gaps? In J. Waldfogel \& K. Magnuson (Eds.), Stalled progress: Inequality and the black-white test score gap (pp. 139-180). New York: Russell Sage Foundation.

Grissmer, D., Grimm, K. J., Aiyer, S. M., Murrah, W. M., \& Steele, J. S. (2010). Fine motor skills and early comprehension of the world: Two new school readiness indicators. Developmental Psychology, 46, 1008-1017.

Heckman, J. L., Stixrud, J., \& Urzua, S. (2006). The effects of cognitive and noncognitive abilities on labor market outcomes and social behavior. Journal of Labor Economics, 24, 411-482.
Holtzer, R., Friedman, R., Lipton, R. B., Katz, M., Xue, X., \& Verghese, J. (2007). The relationship between specific cognitive functions and falls in aging. Neuropsychology, 21, 540-548.

Johnson, L. J., Gallagher, R. J., Cook, M., \& Wong, P. (1995). Critical skills for kindergarten: Perceptions from kindergarten teachers. Journal of Early Intervention, 19, 315-327.

Kavale, K., \& Mattson, P. D. (1983). "One jumped off the balance beam": Meta-analysis of perceptual motor training. Journal of Learning Disabilities, 16, 165-173.

Kephart, N. C. (1964). Perceptual-motor aspects of learning disabilities. Exceptional Children, 31, 201-206.

Lawrence, V., Houghton, S., Tannock, R., Douglas, G., Durkin, K., \& Whiting, K. (2002). ADHD outside the laboratory: Boys' executive function performance on tasks in videogame play and on a visit to the zoo. Journal of Abnormal Child Psychology, 30, 447-462.

Lillard, A. S. (2005). Montessori: The science behind the genius. New York: Oxford University Press.

Livesey, D., Keen, J., Rouse, J., \& White, F. (2006). The relationship between measures of executive function, motor performance and externalising behaviour in 5- and 6-year-old children. Human Movement Science, 25, 50-64.

Luo, Z., Jose, P. E., Huntsinger, C. S., \& Pigott, T. D. (2007). Fine motor skills and mathematics achievement in East Asian American and European American kindergartners and first graders. British Journal of Developmental Psychology, 25, 595-614.

Marr, D., Cermak, S., Cohn, E. S., \& Henderson, A. (2003). Fine motor activities in Head Start and kindergarten classrooms. American Journal of Occupational Therapy, 57, 550-557.

Mather, N., \& Woodcock, R. W. (2001). Examiner's manual Woodcock-Johnson III Tests of Achievement. Itasca, IL: Riverside.

Matthews, J. S., Cameron Ponitz, C., \& Morrison, F. J. (2009). Early gender differences in self-regulation and academic achievement. Journal of Educational Psychology, 101, 689-704.

Mazzocco, M. 1. M. M., \& Kover, S. T. (2007). A longitudinal assessment of executive function skills and their association with math performance. Child Neuropsychology, 13, 18-45.

McClelland, M. M., Acock, A. C., \& Morrison, F. J. (2006). The impact of kindergarten learning-related skills on academic trajectories at the end of elementary school. Early Childhood Research Quarterly, 21, 471-490.

McClelland, M. M., Cameron, C. E., Connor, C. M., Farris, C. L., Jewkes, A. M., \& Morrison, F. J. (2007). Links between behavioral regulation and preschoolers' literacy, vocabulary, and math skills. Developmental Psychology, 43, 947-959.

McPhillips, M., \& Jordan-Black, J.-A. (2007). The effect of social disadvantage on motor development in young children: A comparative study. Journal of Child Psychology and Psychiatry, 48, 1214-1222. 
Medwell, J., Strand, S., \& Wray, D. (2007). The role of handwriting in composing for $\mathrm{Y} 2$ children. Journal of Reading, Writing, and Literacy, 2, 11-21.

Meisels, S. J., Marsden, D. B., Wiske, M. S., \& Henderson, L. W. (1997). Early Screening Inventory-Revised. New York: Pearson Early Learning.

Meisels, S. J., Wiske, M. S., \& Tivnan, T. (1984). Predicting school performance with the Early Screening Inventory. Psychology in the Schools, 21, 25-33.

Morrison, F. J., Cameron Ponitz, C., \& McClelland, M. M. (2010). Self-regulation and academic achievement in the transition to school. In S. D. Calkins \& M. A. Bell (Eds.), Child development at the intersection of emotion and cognition (pp. 203-224). Washington, DC: American Psychological Association.

Murrah, W. M. (2010). Comparing self-regulatory and early academic skills as predictors of later math, reading, and science elementary school achievement. Doctoral dissertation, University of Virginia, Charlottesville.

Muthén, B. O., \& Muthén, L. K. (2009). Mplus (Version 5.2). Los Angeles: Muthén \& Muthén.

Nijenhuis, J. t., \& van der Flier, H. (2002). The correlation of $\mathrm{g}$ with attentional and perceptual-motor ability tests. Personality E Individual Differences, 33, 287.

O'Donnell, P. A., \& Eisenson, J. (1969). Delacato training for reading achievement and visual-motor integration. Journal of Learning Disabilities, 2, 441-447.

Pianta, R. C., Cox, M. J., \& Snow, K. L. (2007). School readiness and the transition to kindergarten in the era of accountability. Baltimore: Brookes.

Rapport, M. D., Bolden, J., Kofler, M. J., Sarver, D. E., Raiker, J. S., \& Alderson, R. M. (2009). Hyperactivity in boys with attention-deficit/hyperactivity disorder (ADHD): A ubiquitous core symptom or manifestation of working memory deficits? Journal of Abnormal Child Psychology, 37, 521-534.

Rimm-Kaufman, S. E., Pianta, R. C., \& Cox, M. J. (2000). Teachers' judgments of problems in the transition to kindergarten. Early Childhood Research Quarterly, 15, 147-166.

Rivière, J., Lécuyer, R., \& Hickmann, M. (2009). Early locomotion and the development of spatial language: Evidence from young children with motor impairments. European Journal of Developmental Psychology, 6, 548-566.

Roth, M., McCaul, E., \& Barnes, K. (1993). Who becomes an "at-risk" student? The predictive value of a kindergarten screening battery. Exceptional Children, 59, 348-358.

Schafer, J. L., \& Graham, J. W. (2002). Missing data: Our view of the state of the art. Psychological Methods, 7, 147-177.

Shonkoff, J. P., \& Phillips, D. A. (2000). From neurons to neighborhoods: The science of early childhood development. Washington, DC: National Academy Press.

Simner, M. L. (1982). Printing errors in kindergarten and the prediction of academic performance. Journal of Learning Disabilities, 15, 155-159.
Son, S.-H., \& Meisels, S. J. (2006). The relationship of young children's motor skills to later reading and math achievement. Merrill-Palmer Quarterly, 52, 755-778.

Sortor, J. M., \& Kulp, M. T. (2003). Are the results of the Beery-Buktenica Developmental Test of Visual-Motor Integration and its subtests related to achievement test scores? Optometry and Vision Science: Official Publication of the American Academy of Optometry, 80, 758-763.

Soska, K. C., Adolph, K. E., \& Johnson, S. P. (2010). Systems in development: Motor skill acquisition facilitates three-dimensional object completion. Developmental Psychology, 46, 129-138.

Stanovich, K. E. (2008). Matthew effects in reading: Some consequences of individual differences in the acquisition of literacy. Journal of Education, 189, 23-55.

Stevenson, H. W., \& Newman, R. S. (1986). Long-term prediction of achievement and attitudes in mathematics and reading. Child Development, 57, 646-659.

Sugden, D., Kirby, A., \& Dunford, C. (2008). Issues surrounding children with developmental coordination disorder. International Journal of Disability, Development $\mathcal{E}$ Education, 55, 173-187.

Taylor Kulp, M. (1999). Relationship between visual motor integration skill and academic performance in kindergarten through third grade. Optometry and Vision Science: Official Publication of the American Academy of Optometry, 76, 159-163.

Willcock, E., Imuta, K., \& Hayne, H. (2011). Children's human figure drawings do not measure intellectual ability. Journal of Experimental Child Psychology, 110, 444-542.

Williams, J. H. G., Whiten, A., \& Singh, T. (2004). A systematic review of action imitation in autistic spectrum disorder. Journal of Autism $\mathcal{E}$ Developmental Disorders, 34, 285-299.

Willingham, D. B. (1998). A neuropsychological theory of motor skill learning. Psychological Review, 105, 558584.

Wolff, P. H., Gunnoe, C., \& Cohen, C. (1985). Neuromotor maturation and psychological performance: A developmental study. Developmental Medicine and Child Neurology, 27, 344-354.

Wolfgang, C. H., Stannard, L. L., \& Jones, I. (2003). Advanced constructional play with LEGOs among preschoolers as a predictor of later school achievement in mathematics. Early Child Development \& Care, 173, 467475.

Woodcock, R. W., McGrew, K. S., \& Mather, N. (2001). Woodcock-Johnson III Tests of Achievement. Itasca, IL: Riverside.

Zelazo, P. R. (1984). "Learning to walk": Recognition of higher order influences? Advances in Infancy Research, 3, 251-256.

Zelazo, P. D., Carter, A., Reznick, J. S., \& Frye, D. (1997). Early development of executive function: A problemsolving framework. Review of General Psychology, 1, 198226. 


\section{Appendix}

Final Multilevel Model for Children's Spring Achievement

$Y_{i j}=\beta_{0 j}+\beta_{1 j}$ (male $)+\beta_{2 j}$ (non-Asian minority)

$+\beta_{3 j}$ (age at achievement assessment)

$+\beta_{4 j}$ (mother's education)

$+\beta_{5 j}($ fall achievement score $)+\beta_{6 j}($ HTKS $)$

$+\beta_{7 j}$ (age at motor assessment)

$+\beta_{8 j}$ (gross motor composite $)+\beta_{9 j}$ (blocks)

$+\beta_{10 j}($ design copy $)+\beta_{11 j}$ (draw-a-person $)+r_{i j}$

$$
\beta_{0 j}=\gamma_{00}+u_{j}
$$

$\beta_{1-10 j}=\gamma_{1-10}$
The spring achievement score for child $i$ in classroom $j$ includes the intercept or overall average spring score, plus the contributions of being male, non-Asian minority, child age, mother's education, fall achievement score, HTKS (EF), age at motor assessment, gross motor, draw-a-person, blocks composite, design copy composite, plus error for the individual child. The intercept is further defined at Level 2 as the mean of the group means, plus error for classroom $j$. Thus intercept differences were allowed to vary across classrooms. The effects of $\beta_{1}-\beta_{10}$ were fixed at the classroom level. 